Chronische Hepatitis B

\title{
Wegbereiter für Hepatitis D
}

- Therapieziel bei chronischer Hepatitis $B$ ist die vollständige Serokonversion mit Bildung von Antikörpern gegen das HBsAntigen oder zumindest eine anhaltende Virussuppression. Außerdem muss eine mögliche Koinfektion mit Hepatitis-D-Viren bedacht werden.

Eine dauerhafte Serokonversion von HBs-Antigen zu HBs-Antikörpern wird mit den verfügbaren Medikamenten nur in 5-10\% der Fälle erreicht. „Ein wichtiges Therapieziel ist deshalb eine starke und lang anhaltende Unterdrückung der Virusreplikation“, sagte PD Dr. Heiner Wedemeyer, Hannover. Mit dem Nukleotidanalogon Tenofovir (Viread ${ }^{\circledR}$ ) gibt es dafür überzeugende Ergebnisse: Nach 96 Wochen war die HBV-DNA bei $90 \%$ der HBeAg-negativen Patienten und bei $76 \%$ der HBeAg-positiven Patienten anhaltend supprimiert (< $169 \mathrm{lU} / \mathrm{ml})$. Außerdem hatten $74 \%$ der Patienten innerhalb eines Jahres histologisch auf die Therapie angesprochen.

\section{HDV-Superinfektion ausschließen}

Da das Hepatitis-D-Virus (HDV) für eine Infektion das Hüllprotein des HepatitisB-Virus benötigt, kann es nur bei Hepati-
tis-B-Patienten vorkommen. Wedemeyer erinnerte an die HBV-Leitline der Deutschen Gesellschaft für Verdauungsund Stoffwechselerkrankungen, wonach alle neu diagnostizierten Patienten mit HBV-Infektion auf HDV getestet werden sollen. Auch bei Exazerbation einer chronischen HBV ist eine HDV-Superinfektion auszuschließen. Die Entwicklung zur Leberzirrhose verläuft bei Hepatitis D sehr schnell, außerdem entsteht daraus häufig Leberkrebs. Etwa jeder zehnte HBV-Patient hat vermutlich zusätzlich eine HDV-Infektion.

Zu Hepatitis D wurde im Herbst 2009 die placebokontrollierte HIDIT-II-Studie begonnen. Sie baut auf einer Vorläuferstudie auf, die zeigt, dass rund ein Viertel der HDVInfizierten mit Interferon geheilt werden kann. Nun soll geprüft werden, ob pegyliertes Interferon alfa-2a plus Tenofovir zu höheren Heilungsraten führt.
Tabelle 1

\section{Wer soll auf Hepatitis B getestet werden?}

(1) Personen mit erhöhten Leberwerten und/ oder klinischen Zeichen einer Hepatitis

(2) Patienten mit Leberzirrhose/-fibrose

(3) Patienten mit hepatozellulärem Karzinom

(4) Personen mit Migrationshintergrund aus Regionen mit erhöhter HBsAg-Prävalenz

(5) Familien- oder Haushaltsangehörige bzw. Sexualpartner von HBV-Infizierten

6) Medizinisches Personal

(7) Patienten in psychiatrischen Einrichtungen

8 Homosexuelle Männer, Personen mit häufig wechselnden Sexualkontakten

(9) Aktive und ehemalige i.v. Drogenanwender

(10) Dialysepatienten

(11) HCV- und HIV-Infizierte

(12) Organempfänger vor und nach Transplantation

(13) Blut- und Organspender

(14) Patienten vor bzw. während einer immunsuppressiven Therapie oder Chemotherapie

(15) Schwangere (nur HBsAg)

(16) Neugeborene von HBsAg- und/oder Anti-HBc-positiven Müttern

\section{Raucherentwöhnung}

\section{Oft gibt der Rat des Arztes den Anstoß}

- Mehr als 80\% der Raucher haben sich in den letzten zwölf Monaten mit dem Gedanken getragen, mit dem Rauchen aufzuhören, so das Resultat einer Erhebung am Inselspital in Bern. Wie Dr. J. Hamacher, Bern, hinzufügte, haben aber nur $12 \%$ dieser Raucher beim Aufhörversuch ärztliche Hilfe erhalten. Dabei erhöhe schon die Empfehlung des Arztes - „Ich rate Ihnen, mit dem Rauchen aufzuhören!“- die Erfolgsrate um den Faktor 1,66.

Sollten die Mittel des Verhaltenstrainings nicht ausreichen, um einen Raucher zum Aufhören zu motivieren, oder sollte sein gesundheitlicher Zustand einen be- sonders schnellen Rauchstopp nahelegen, bietet sich zusätzlich eine pharmakologische Intervention an. Dafür stehen $\mathrm{Ni}$ kotinpflaster, Bupropion und Vareniclin (Champix ${ }^{\circledast}$ ) zur Verfügung.

Der gezielt für die Raucherentwöhnung entwickelte partielle Nikotinagonist Vareniclin ist besonders Erfolg versprechend. Das zeigen zwei placebokontrollierte Doppelblindstudien, in denen eine zwölfwöchige Therapie mit Vareniclin mit Bupropion SR bzw. Nikotinpflaster verglichen wurde. In beiden Studien wurden mit Vareniclin signifikant höhere Abstinenzraten erzielt. Die Verträglichkeit von
Vareniclin war insgesamt gut, bis auf eine leichte bis mäßige Übelkeit zu Behandlungsbeginn und (v. a. durch den Nikotinentzug bedingte) leichte psychische Beeinträchtigungen. Die Abbruchrate lag im Placebobereich. Diese Ergebnisse wurden kürzlich durch eine offene randomisierte Vergleichsstudie an 757 aufhörwilligen Rauchern bestätigt. Mit Vareniclin schafften $55,9 \%$ den Rauchverzicht, mit Nikotinpflaster nur $43,2 \%$.

\footnotetext{
- Dr. Till U. Keil

Quelle: Symposium „Raucherberatung in der Arztpraxis“, München, 4./5.Dezember 2009 (Veranstalter: Pfizer)
} 